\title{
¿ES ECONÓMICAMENTE VIABLE FABRICAR UN AUTOMÓVIL 100\% ESTADOUNIDENSE?
}

\author{
ELIO BURGOS GÓMEZ \\ Universidad Estatal a Distancia, Costa Rica \\ elioburgosgomez@yahoo.fr
}

\section{RESUMEN}

El cambio en la participación en el mercado de la industria automotriz estadounidense, la migración de las fábricas hacia países con menores costos y el desempleo en ciudades vinculadas con los productores de automóviles, han llevado al actual Gobierno estadounidense a anunciar restricciones al comercio internacional, a amenazar con aumentos en los impuestos de importación y a plantear la renegociación del Tratado de Libre Comercio. En este ensayo se hace un análisis del flujo de las materias primas, del proceso de fabricación de autopartes y de la forma como se administra la industria, para poder establecer si es posible la autarquía en los procesos productivos actuales, particularmente en el sector automotriz.

PALABRAS CLAVE: COMERCIO INTERNACIONAL, POLITICA COMERCIAL ESTADOUNIDENSE, INDUSTRIA AUTOMOTRIZ, OLIGOPOLIO, AVENTURAS CONJUNTAS.

\section{ABSTRACT}

The Change in participation in the United States automotive industry market, factories migration to low-cost countries, and unemployment in cities linked with car producers have lead the current government to declare international trade restrictions, to warn with raises on imports taxes, and to propose NAFTA renegotiation. This essay makes an analysis on raw material flow, auto parts production process, and the way the industry is managed, in order to establish if autarky is possible on current production process, particularly in car industry.

KEYWORDS: INTERNATIONAL TRADE, USA TRADE POLICY, AUTOMOTIVE INDUSTRY, OLIGOPOLY, JOINT VENTURES.

\section{INTRODUCCIÓN}

El 28 de febrero de 2017, en su primer discurso como presidente de los Estados Unidos de América ante la Cámara de Representantes, Donald Trump ratificó su convicción de cumplir las promesas de campaña, entre las cuales, de tipo económico, destacan: un mayor apoyo a la industria estadounidense, la regulación del comercio internacional con aumentos sustanciales en los impuestos a la importación, la excitativa a las empresas locales de no invertir en el extranjero $y$, antes bien, que lo hagan domésticamente para así generar más empleos, además de adversar las estipulaciones del Tratado de Libre Comercio con Canadá y México (NAFTA). En esa ocasión, Trump dijo: "This effort will be guided by two core principles: Buy American, and Hire American" ("Este esfuerzo será guiado por dos principios medulares: Compre estadounidense y emplee estadounidense") (CNN, 2017). 
El ejemplo de la noche para argumentar las acciones de la administración fue la caída en las ventas internacionales de las motocicletas HarleyDavidson. Antes, durante la campaña, Trump había manifestado que en las carreteras de los Estados Unidos circulan muchos Mercedes Benz, pero en Alemania es prácticamente imposible ver un Chevrolet. Y ya en el cargo presidencial amenazó a BMW, VW y otras empresas locales de la siguiente forma: "If you go to another country and you decide that you're going to close and get rid of 2,000 people or 5,000 people... we are going to be imposing a very major border tax on the product when it comes in" "Si ustedes van a otro país y deciden cerrar y prescindir de dos mil o cinco mil personas... vamos a aplicar un altísimo impuesto de aduana sobre su producción cuando esta sea importada") (Business Insider, 2017).

Al respecto, el periódico digital USA Today resume lo esencial de las medidas proteccionistas: "As Trump has spoken repeatedly about a 35\% boost to discourage American plants from relocating to lower-cost Mexico" ("como Trump lo ha dicho repetidamente, alrededor de 35\% de alza tarifaria para desmotivar a las fábricas locales a trasladarse a México por sus bajos costos") (USA Today, 2017).

La protección de la industria automotriz estadounidense, en los esquemas simplificados de Donald Trump, es un poderoso recurso retórico para justificar sus posiciones autárquicas frente al comercio internacional, pues es concebible -para el ciudadano promedio- la relación entre el desempleo en las ciudades industriales y la caída en la producción y ventas de automóviles de marcas norteamericanas. Por ello cabe formularse la pregunta: ¿Es económicamente viable fabricar un automóvil cien por ciento estadounidense?

\section{OBJETIVOS Y METODOLOGÍA}

En este ensayo se hará una deconstrucción de los procesos productivos generales que conducen a ensamblar un automóvil listo para el consumidor final. Se estudiarán los fujos de materias primas y suministros básicos para la fabricación de un automóvil y los insumos generales que requiere para su funcionamiento, así como su origen y comercialización a escala mundial. Se separarán los subsistemas componentes de un automóvil, para diseccionar sus piezas básicas, sus mayores fabricantes y los esquemas de suministros predominantes en los mercados actuales. Se hará un repaso histórico de las principales compañías productoras de automóviles, sus formas de penetración de mercados, los grupos industriales y sus marcas comerciales. Se enumerarán los convenios de cooperación (joint ventures) más relevantes, fusiones y absorciones, así como las políticas de inversión internacional y diversificación de mercados de las principales compañías productoras.

Todo lo anterior permitirá evaluar si es posible la autarquía en los procesos productivos de la industria de hoy, e inferir sobre los posibles beneficios de la especialización productiva y la cooperación para producir más y con mejor calidad.

\section{DESARROLLO}

\section{Materias primas y suministros}

La fabricación y funcionamiento de un automóvil demanda gran cantidad de materias primas, entre las cuales se cuentan metales, hidrocarburos, polímeros y otros, provenientes de diversas regiones de la tierra. Por razones de simplificación, solamente se hará un recuento de la producción de acero, aluminio, cobre y petróleo, materias básicas para la confección de las piezas integrantes de motores, carrocerías y sistemas electromecánicos.

Estados Unidos es el mayor importador de acero en el mundo (International Trade Administration, 2016); según esta misma fuente, el volumen de las importaciones estadounidenses de acero fue más del $40 \%$ mayor que el del segundo 
importador del mundo, Alemania; además, la agencia de comercio afirma que las importaciones norteamericanas de acero representan 1,4\% del total de los bienes importados por los Estados Unidos en el año 2015.

Los cinco mayores proveedores de acero a los Estados Unidos son Canadá: 17\%, Brasil: 13\%, Corea del Sur: 12\%, México: 9\% y Turquía: 8\%, como se describe en la figura 1.

El Banco de Comercio Exterior de México indica lo siguiente:
China es el actor más relevante del mercado mundial del aluminio al concentrar alrededor de $47 \%$ de la producción y de $45 \%$ de la demanda. Otros importantes productores mundiales del metal son Rusia, Canadá y Australia. Mientras que Estados Unidos, Japón y la Unión Europea dan cuenta de otra parte significativa de la demanda mundial (Bancomex, 2017).

Aunque las marcas norteamericanas, en general, no utilizan el aluminio para sus carrocerías,

\section{FIGURA 1 \\ IMPORTACIONES NORTEAMERICANAS DE ACERO AÑO DE INFORME: 2016. MILLONES DE TONELADAS MÉTRICAS}

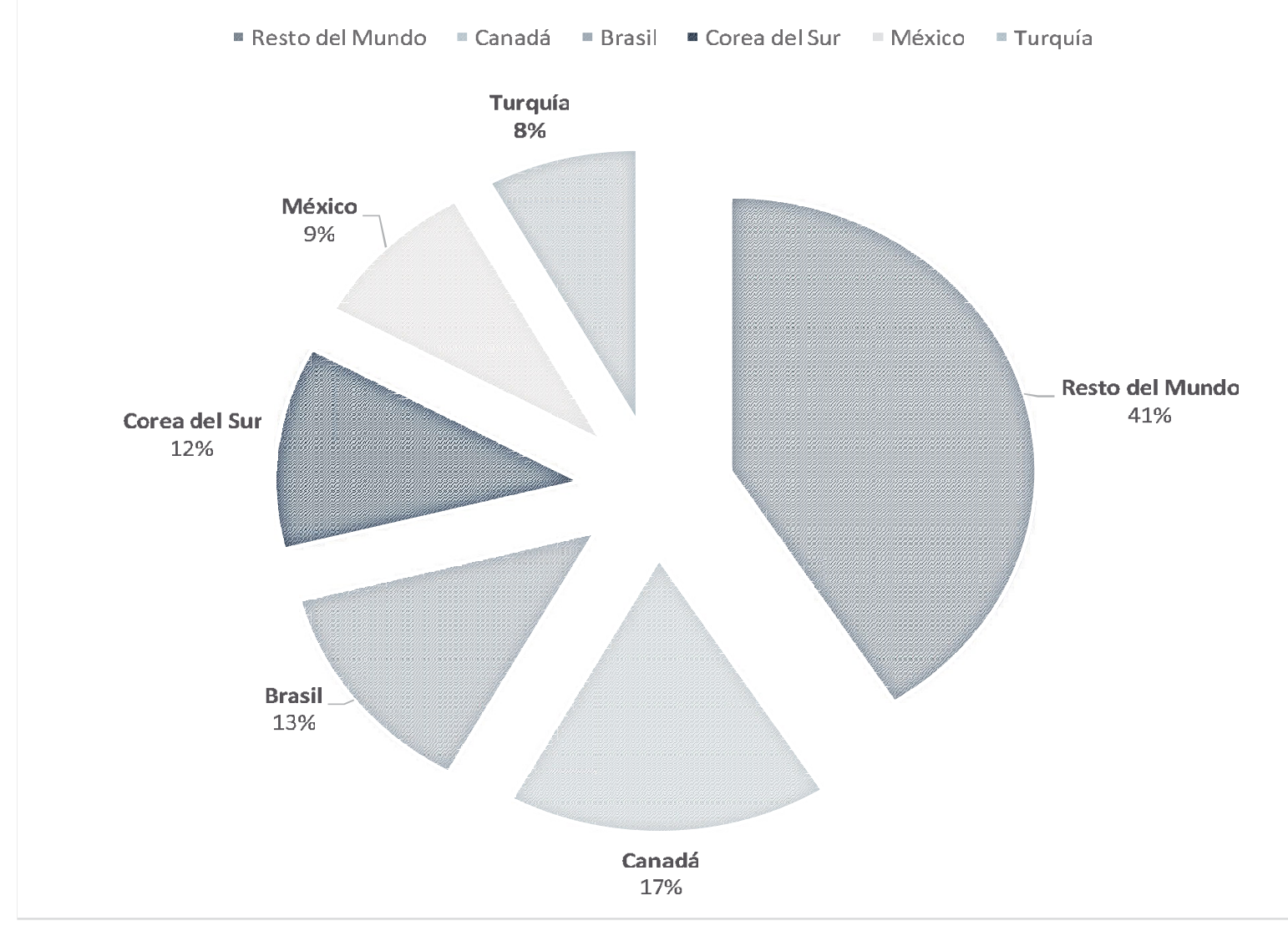

Fuente: International Trade Administration, 2016. 
sí forma parte de circuitos y otros componentes que los productores de automóviles compran a proveedores especializados en su fabricación. Las marcas británicas como Rover y las alemanas como Audi sí privilegian el aluminio para sus carrocerías, lo cual "ha hecho que las grandes marcas pongan al país (México) en el mapa de su estrategia: empresas como Audi han hecho inversiones iniciales por más de 1300 mdd para establecer su nueva planta de producción (de aluminio) en Puebla" (Forbes México, 2017a).

El cobre es otra materia prima integrante de los sistemas eléctricos y electromecánicos de los automóviles. Los mayores productores a nivel mundial son Chile: 34\%, Perú: 8\%, China: 7\% y Estados Unidos: 7\% (Rankia España, 2016).
Por supuesto que los fabricantes de automóviles no compran el cobre en bruto, sino con muchos procesos intermedios, que van desde los simples cables conductores hasta arrancadores, alternadores y equipo de cómputo; pero es conveniente saber el origen de las materias primas.

Las baterías también utilizan plomo, pero los fabricantes finales no compran el plomo, sino las baterías ya terminadas a productores especializados. Lo mismo sucede con el antimonio, el estaño, el litio, los polímeros, empaques, vidrios, tapicerías y otros componentes que se listarán más adelante.

Los automóviles también requieren petróleo para su operación, no solo como carburante en forma de gasolina o diesel para obtener la fuerza

\section{FIGURA 2 \\ PRODUCCIÓN MUNDIAL DE COBRE \\ DATOS EN MILES DE TONELADAS MÉTRICAS DE CONTENIDO DE COBRE \\ TOTAL MUNDIAL: 16200}

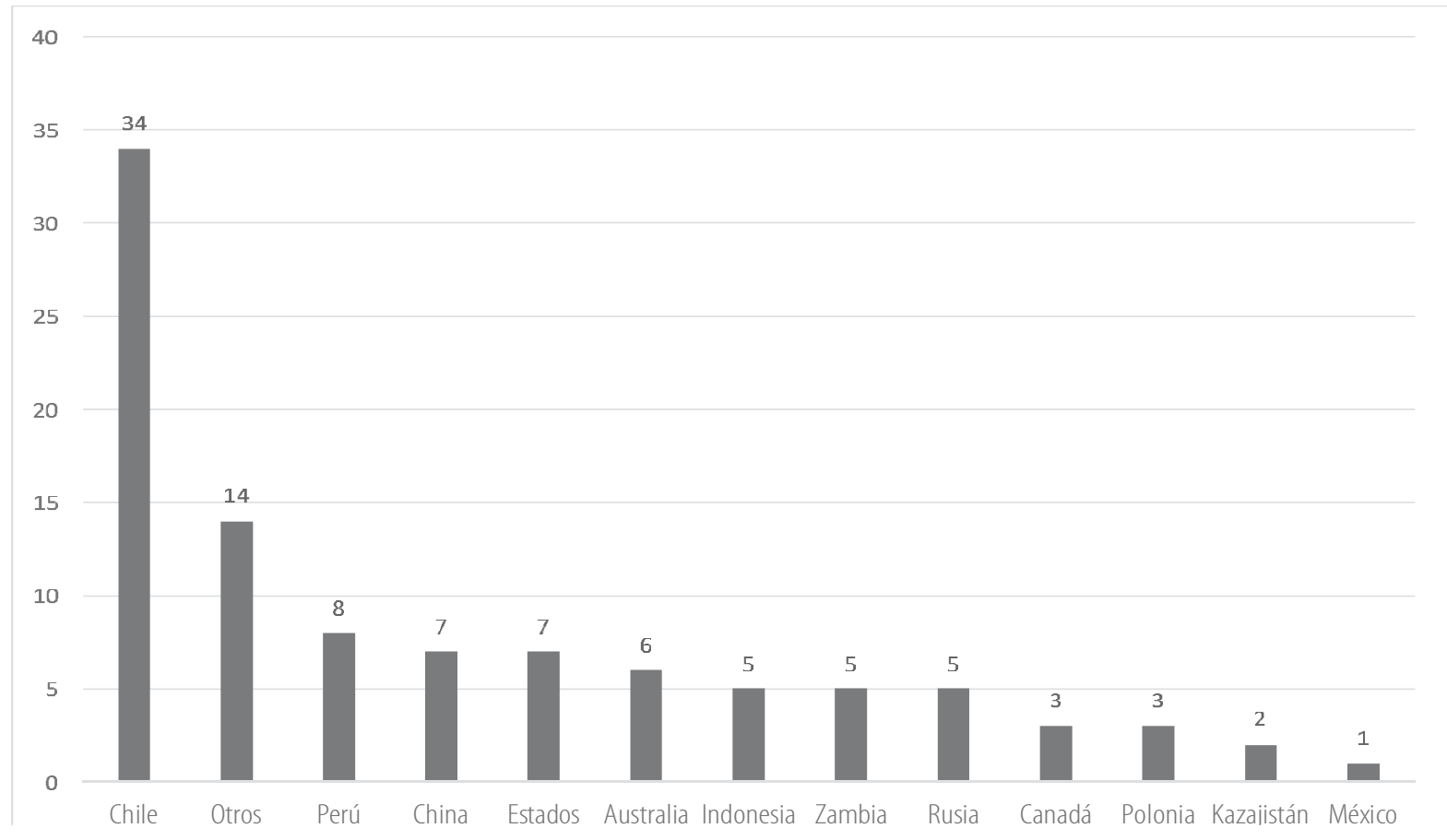

Fuente: Rankia España (2016). 


\section{FIGURA 3 \\ LOS MAYORES DIEZ PAÍSES DE DONDE EUA IMPORTA EL PETRÓLEO \\ (EN MILLONES DE BARRILES, DICIEMBRE 2014-MAY0 2015}

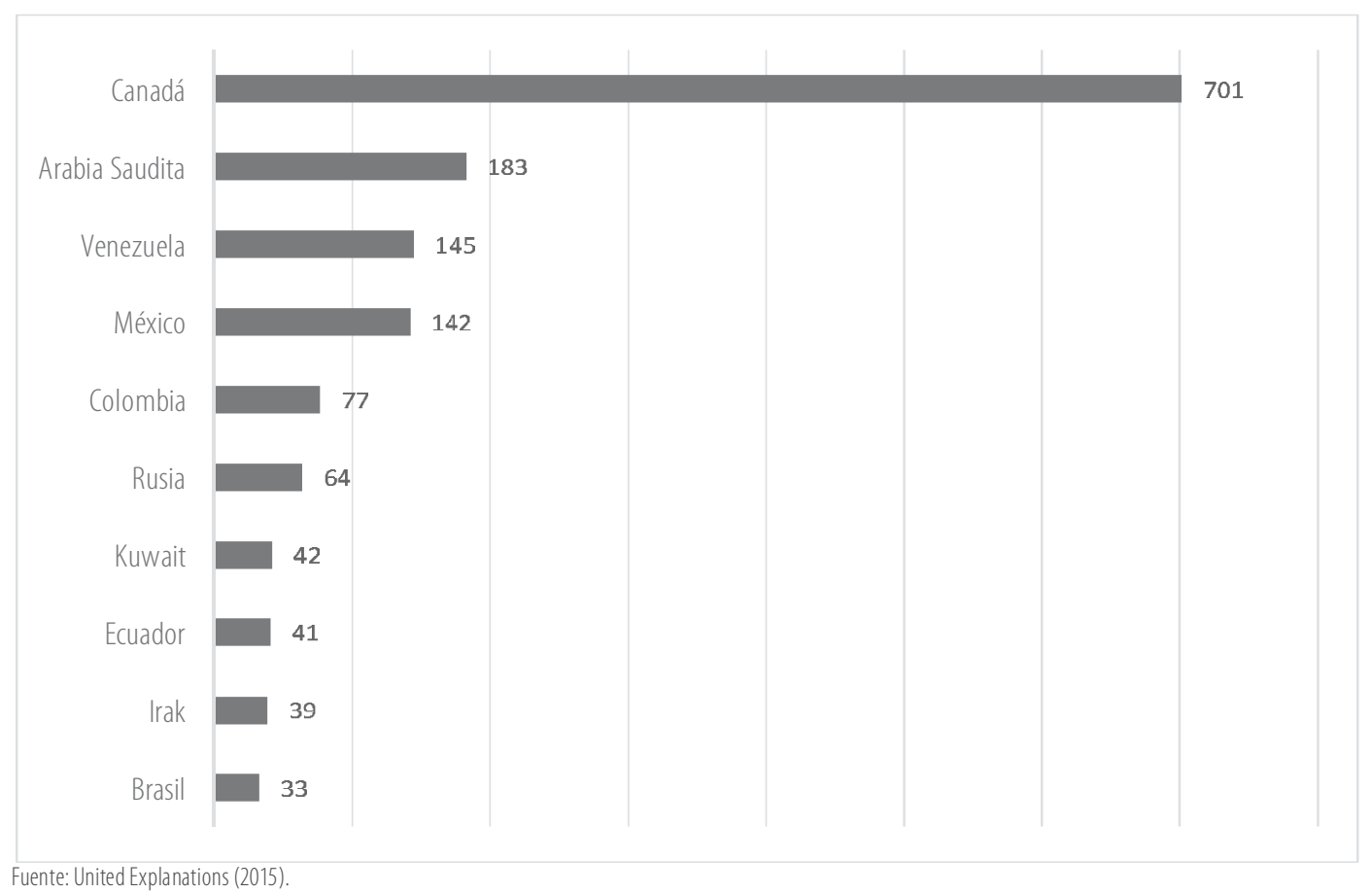

Fuente: United Explanations (2015).

de desplazamiento, sino también como aceites para protección del motor, así como grasas y lubricantes de roles, piñones o cajas de transmisión para que funcionen adecuadamente. Aunque Estados Unidos es un país productor de petróleo y sus derivados, su consumo depende de un 40\% importado (United Explanations, 2015).

La figura 3 es muy informativa sobre el origen del petróleo importado por Estados Unidos. United Explanations también informa que las importaciones provenientes del hemisferio americano tienen como los tres principales proveedores a Canadá con $28 \%$, Venezuela con $11 \%$ y México con $11 \%$.

Al igual que con las otras materias primas, los fabricantes de automóviles no compran el petróleo crudo, sino el lubricante final a empresas con marcas como Castrol, Pennzoil, Mobil, Valvoline,
Amalie, Bardahl, Petro-Canadá u otras con múltiples refinerías ubicadas por todo el mundo.

\section{Subsistemas de un automóvil}

Para el análisis del proceso productivo de un automóvil, proponemos dividirlo en cinco grandes subsistemas que, aunque también pueden subdividirse, serán prácticos para los propósitos del presente ensayo. Los subsistemas son los siguientes:

- soporte;

- motor;

- transmisión;

- eléctrico;

- confort. 
El subsistema de soporte de un automóvil comienza a partir de su contacto con el terreno, es decir, con las llantas, aros y suspensión; los cuales se unen con el chasis y los mecanismos de dirección, frenado y la carrocería.

Las llantas de los vehículos son producidas por empresas especializadas. La que tiene el mayor porcentaje de ventas mundiales es la Bridgestone Corporation, cuya sede central se ubica en Kyobashi, Japón, aunque tiene plantas por todo el mundo (Tire Business, 2016). El segundo productor de llantas es la compañía francesa Michelin, seguida por la norteamericana Goodyear y la italiana Pirelli. Además, los productores de automóviles tienen un gran menú de posibles proveedores que, aunque no estén arriba en el ranking, fabrican llantas de calidad. Entre esas marcas están Sumitomo, Yokohama, Cooper, Giti y hasta Toyo Tires, que no son las llantas que necesariamente usa Toyota.

Nada asegura que Chevrolet, Ford o Jeep tengan como único proveedor a Goodyear. Incluso si Donald Trump firmara un improbable decreto para que estos fabricantes solamente usen esa marca estadounidense, las Ilantas Goodyear podrían llegar desde las plantas brasileñas en Sao Paulo, Americana o Santa Bárbara, de la fábrica venezolana en Valencia, de la peruana en Lima, desde Cali en Colombia o Santiago de Chile (Goodyear, 2015).

Con los compensadores sucede lo mismo: podrían ser Monroe, Gabriel, Shibumi o Boge. Todos se desempeñan de manera similar porque las compañías fabricantes se especializan en sistemas de amortiguación y luego tienen contratos de abastecimiento tanto para los ensambladores de automóviles como para los distribuidores de repuestos al menudeo.

Los productores de aros se concentran en esa importante pieza de la llanta y también se convierten en proveedores de las marcas automotrices y para el consumidor final. Ni siquiera las grandes compañías llanteras manifiestan interés evidente por fabricar los aros; mucho menos lo harán las empresas que ofrecen el automóvil como producto final. De la misma forma, hay sectores que se especializan en sistemas de frenos como Bosh, Bendix o Brake One; y entre los productores del líquido para que generen la presión de frenado, podría encontrar a Wagner, Motul, Frenosa, Mamusa, Zkron, LTH o Bardahl. También existen fabricantes especializados para las partes del mecanismo de dirección, sean rótulas, cremalleras, barras de suspensión y hasta el volante.

El chasis y la carrocería podrían parecer de exclusividad para la marca, lo cual no es exacto, pues requieren tornillos, remaches y soldadura; pero incluso si lo fueran, a estas partes se debe aplicar anticorrosivos, selladores, adhesivos, pinturas y lacas de acabado, que son comprados al por mayor a otras empresas. Entre las compañías de pinturas y recubrimientos más grandes del mundo están AkzoNobel de Holanda, Henkel y BASF de Alemania, Nippon y Kansai de Japón, Hempel de Dinamarca y Comex de México. Pero si se quiere ser fiel al "Buy American" de Trump, las automotrices podrían adquirir las pinturas de PPG, Sherwin Williams o 3M (Forbes México, 2017b).

El subsistema de motor incluye la admisión de aire al motor, la inyección del tanque de combustible a la cámara de explosiones, la lubricación interna, los procesos de enfriamiento, la salida de los gases de combustión y el motor propiamente dicho. Aunque un vehículo sea promocionado como cien por ciento coreano, el filtro de aire podría ser de marca FRAM, Bosh, Gonger, Wix o Baldwin. Lo mismo puede suceder si un Mercedes Benz fue ensamblado en Brasil o México; la marca de los filtros dependerá de la empresa proveedora de la zona. Las mangueras para el traslado del aire también presentan una situación similar, pero para el usuario final eso pasa desapercibido. 
En cuanto a los inyectores, los turbos y los carburadores, también existen empresas especialistas que maquilan para los ensambladores. $Y$ en el caso de las bujías, las diferentes empresas han homogenizado la calidad y es posible encontrarlas como Champions, Bosch o NGK. Con respecto a la lubricación interna, ya se dijo líneas arriba cuáles son los posibles proveedores.

Los procesos de enfriamiento incluyen el radiador, el ventilador, la bomba de agua, el termostato y la tubería por donde pasará el líquido refrigerante. Dada la creciente especialización, existen empresas proveedoras para cada una de las piezas; $y$ aunque fueran fabricadas directamente por la ensambladora, al menos el líquido refrigerante deberá ser comprado a Vistony, Prestone, Peak o Mobil.

La salida de gases comienza con un sistema de válvulas en la cámara de explosiones, luego sigue una tubería que pasa por un catalizador y finalmente llega al escape, el cual puede variar entre roncador o silenciador. Existen fabricantes especializados para cada una de las piezas.

En cuanto al motor, la lógica del presidente Trump podría llevar a pensar que si es el vehículo es marca GMC, también lo será el motor; o si el vehículo es Toyota, el motor también. Sin embargo, desde 1983 se construye en Estados Unidos automóviles marca General Motors con motores Toyota (Rodríguez, 2013). En muchas calles del mundo circulan automóviles de una marca determinada, pero cerca del parachoques trasero portan la inscripción "Powered by Mercedes Benz" o similar. Esto ocurre por algunas alianzas estratégicas que se han venido implementando para penetrar mercados, como se detallará más adelante.

Aunque se aceptara que el cabezote, el cárter, los pistones, las bielas, el cigüeñal y el árbol de levas sean fabricados bajo la estricta responsabilidad de la marca comercial final, existen piezas que se compra a proveedores externos, como por ejemplo el empaque del cabezote, los anillos, los retenedores, el filtro de aceite y los soportes, que son las piezas que fijan el motor con el chasis.

El subsistema de transmisión incluye la caja de cambios y la transferencia de fuerza, además de las campanas, barras transmisoras y diferenciales. En su parte interna, la caja de cambios y los engranajes están rellenos con lubricante, pues existe una serie de piñones, roles y ejes que llevan la fuerza de desplazamiento desde el motor hasta las llantas y deben ser protegidos contra la fricción, el desgaste y la corrosión. Incluso los tornillos, tuercas, arandelas, retenedores y sellos pueden ser maquilados por empresas proveedoras, diferentes a la marca comercial del automóvil en cuestión.

El subsistema eléctrico incluye el arrancador, la batería, el alternador y el entramado de cables que permiten la iluminación, emitir señales, escuchar música, accionar vidrios, cargar el teléfono, regular el aire acondicionado, operar la cámara de retroceso y la computadora que gobierna todos los procesos de los automóviles actuales. La inmensa mayoría de esos componentes, desde los bombillos hasta el navegador, pasando por las alarmas y cierres centrales, son maquilados y el consumidor final tendrá que conducir un vehículo Cherokee mientras escucha música en un radio marca Pioneer, Sony, Toshiba, General Electric o Phillips.

El subsistema de confort comienza en el decorado externo, con cromados o polímeros. Para abrir el automóvil se necesita llaves, las cuales, junto con los llavines y los cierres centrales, se compran a otras compañías. Al ingresar al vehículo se puede ver los monitores del tablero de instrumentos, los asientos, los apoyacabezas y su tapicería, así como las alfombras, los vidrios, las películas polarizadoras, los espejos, los empaques, botaguas y escobillas, eventuales quemacocos, los cinturones de seguridad, las bolsas de aire y todos los equipos que en su introducción tienden a comercializarse como extras; incluso los portavasos. 
La producción de todos estos elementos puede subcontratarse.

Finalmente, los triángulos de prevención, el chaleco fosforescente, la linterna y el extintor contra incendios también son maquilados por otras empresas distintas de Ford, General Motors o Lamborghini.

El presidente estadounidense ha dicho no creer lo que la prensa publica, entre la cual está The Wall Street Journal; pero precisamente en este medio los periodistas James R. Hagerty y Jeff Bennett ya habían presentado el artículo que en su versión en español se tituló "Los autos 'Made in USA' contienen cada vez más partes importadas" (2015). Según esta publicación: "Los autos hechos en EE. UU. son fabricados de manera creciente con partes de México, China y otros países". Y más adelante afirman lo siguiente: "EE. UU. importó un número récord de US\$138 000 millones en autopartes el año pasado (2014), equivalente a US\$12 135 del contenido de cada coche ligero construido. Más que los US\$89 000 millones, equivalente a US\$10 536 por vehículo, de 2008".

\section{Esquemas gerenciales en la fabricación del automóvil}

La forma de producir automóviles ha evolucionado a lo largo del tiempo, y es previsible que los cambios sigan ocurriendo. Los esquemas gerenciales más icónicos tuvieron su época y sus pioneros; luego enfrentaron la necesidad de cambio y también la resistencia de unos pocos productores de quedarse aferrados a su paradigma. En este ensayo se considera conveniente dividir en seis los esquemas administrativos más relevantes en la industria automotriz:

- elaboración artesanal;

- línea de montaje;

- redes globales de producción;
- aventuras conjuntas;

- fusiones y absorciones;

- desconcentración geográfica.

La elaboración artesanal tiene su época a finales del siglo XIX y principios del XX. Entonces los talleres eran incipientes, las piezas se hacían casi manualmente y los progresos técnicos se daban por el gran entusiasmo de los pioneros: Brown en Inglaterra adaptó un motor a vapor, Lenoir en Bélgica inventó un motor de dos tiempos, Otto en Alemania desarrolló el motor de cuatro tiempos y el carburador, Maybach en Alemania incorporó los cuatro cilindros, que fue el gran aporte para que Daimler y Benz lograran con su automóvil el récord de velocidad en sesenta y cuatro kilómetros por hora. Incluso, en esos años los avances llegaban de todo el mundo: Bosh inventó las bujías en Alemania, Dumlop perfeccionó en Escocia la llanta neumática y Kettering patentó en Estados Unidos el motor de arranque electrónico.

Reportan Juárez, Lara y Bueno (2005, p.26) que para 1901 Estados Unidos ocupaba el primer lugar mundial con una producción de 4192 automóviles anuales, seguido por los talleres Peugeot franceses y Daimler-Benz alemanes. Las presiones de cambio para este esquema de fabricación llegaban por la creciente demanda por automóviles. Pocas marcas quedan, aun hoy, que mantengan la producción manual, pero se posicionan en segmentos de muy alto precio o para los amantes de la velocidad. La cantidad de vehículos producidos de este tipo es baja, pues trabajan a pedido o en la construcción de prototipos para competencias deportivas.

La etapa de la línea de montaje fue inaugurada por Henry Ford en 1913. En términos generales, el proceso constructivo consistía en un carril sobre el cual se empalmaban llantas y chasis para ser jalados con un cable. A medida que la estructura avanzaba, cada mecánico iba agregando 
la autoparte que le correspondía, logrando con esta especialización mayor eficiencia y al final de la línea salía un Ford T color negro, listo para su comercialización y uso.

Durante la Primera Guerra Mundial, la Ford llegó a ocupar el primer lugar en ventas y su línea de montaje fue adoptada por otros fabricantes estadounidenses. Pero este proceso administrativo no estaba exento de debilidades. Al respecto, escriben Hill y Jones lo siguiente:

Henry Ford I diseñó su compañía de tal manera que le proporcionaba control absoluto sobre la toma de decisiones. Incluso vigilaba las acciones del equipo de alta gerencia, y su sucesor, Henry Ford II, continuó manejando la compañía en una forma bastante centralizada. El resultado para Ford Motor Car Co. fue una cultura organizacional caracterizada por formar gerentes conservadores y temerosos de asumir riesgos, y la compañía se reconocía por su lento ritmo para cambiar e innovar (Hill y Jones, 1996, p. 373).

Después de la Primera Guerra Mundial, el CEO de General Motors, Alfred Sloam, introdujo cambios en el diseño de los automóviles, con variedad de colores y diferentes divisiones corporativas para producir desde versiones de bajo precio hasta marcas para segmentos de lujo. Esto le permitió a la General Motors convertirse en el mayor productor a nivel mundial y desplazar a la Ford.

El modelo de redes globales de producción se articula a través de un productor líder de marca que incorpora varias empresas especialistas en partes del proceso. Estas empresas pueden ser subsidiarias, simples contratistas, proveedores o coinversores. El esquema lo implementó la Toyota, fundada en 1931 en Japón, y consiste en concentrar geográficamente las diferentes empresas proveedoras en lo que ellos denominaron "Ciudad Toyota" para luego aplicar el sistema de inventarios "justo a tiempo" o Kanban, como lo denominó su inventor, Ono Taiichi; además de la implementación de los círculos de calidad para cada proveedor a fin de lograr mejoras tecnológicas pieza por pieza y también asumir la filosofía de administración de la calidad predicada por el Dr. W. Edwards Deming (Summers, 2006).

Después de la Segunda Guerra Mundial, Toyota dominó el mercado doméstico y luego comenzó a exportar. A finales de los años sesenta construyó el modelo Corolla, en tanto que la Nissan lanzó el Sunny; ambos llegarían a ocupar importantes volúmenes de venta a nivel mundial. Además de un precio más accesible, estos modelos eran más eficientes que sus competidores en el uso del combustible, lo cual les daba ventaja comercial durante la crisis de los hidrocarburos de los años setenta. Las redes de producción japonesas, para la década de los ochenta, habían convertido al archipiélago nipón en el mayor ensamblador de automóviles a nivel mundial.

El proteccionismo comercial estadounidense de los años ochenta propició el modelo de las aventuras conjuntas (join ventures). Una de las primeras, que se señaló líneas arriba, se dio entre la General Motors y la Toyota para producir conjuntamente el Nova, que se ensamblaba en plantas estadounidenses de la GMC con alrededor del 50\% de autopartes japonesas que a nivel contable no se reflejaban como importaciones de automóviles. Además, implementaron el outsoursing de servicios para reducir sus costos de planilla. Movidos por este éxito, Mazda convino su aventura conjunta con Ford y la Mitsubishi con Chrysler (CEPAL, 2010).

Estas alianzas también fueron adoptadas por compañías europeas: Ford estableció su aventura conjunta con Volkswagen, Daimler Benz con Citroën y Renault con Nissan. Este esquema productivo permitía mantener la imagen de cada empresa, minimizar los riesgos y penetrar nuevos mercados, mientras compartían tecnología y recursos. A la vez, difuminaban la identificación 
nacional con las marcas, la de los inversionistas y el registro contable del comercio internacional.

A finales del siglo XX y comienzos del presente, se registra la etapa de las fusiones y absorciones, es decir, la concentración de la propiedad en cada vez menos grupos económicos. No quiere decir que desaparecieran las marcas comerciales, puesto que se tenía presente el ejemplo francés cuando en 1976 Peugeot absorbió a Citroën para crear el grupo PSA pero conservando marcas, estilos y segmentos de mercado. Dicho grupo continúa pujante, pues según informa un periódico nacional, la fortaleza financiera del grupo PSA le permitió comprar la Opel a General Motors, con lo cual "se convertirá, así, en el segundo constructor de vehículos en Europa (...) controlando el 16\% del mercado europeo, frente al 24\% de Volkswagen" (La Nación, 2017).

En este período, la aventura de Nissan y Renault culminó en matrimonio, igual que la de Chrysler y Daimler-Benz. Rover fue adquirida por BMW, Scania de Suecia vendió un alto porcentaje de sus acciones a las alemanas Volkswagen y MAN, y en Corea Ssang Yong es dominada por Daewoo. A finales de la primera década del siglo XXI, entraron en este proceso nuevos actores de países emergentes: Jaguar del Reino Unido pasó a formar parte del grupo Tata Motors de la India y Volvo de Suecia fue comprada por el grupo Zhejiang Geely de China (CEPAL, 2010).

Actualmente, se está frente a una desconcentración geográfica de todos los grupos automotrices. Es preciso recalcar que cada paradigma gerencial no comienza tras la muerte del otro; de hecho, el fordismo está débil pero sigue vivo en la mente de Donald Trump. Tampoco terminaron las joint ventures y las fusiones seguirán su natural tendencia oligopolística; pero marcan una corriente dominante que es preciso comprender como signo de los tiempos.

Siempre hay pioneros que rompen viejos moldes. Por ejemplo, Nissan es un acrónimo que significa "industria japonesa"; sin embargo, esta corporación, que tiene su sede en Yokohama, desde 1959 tenía plantas en Taiwán y en 1961 inició operaciones en México. Luego se expandió a Tailandia, Indonesia y la India; también construyó ensambladoras en España y el Reino Unido. Estados Unidos no fue la excepción, pues Nissan tiene talleres en Michigan, Stanfield y San Diego, California. En China construyó fábricas en Cantón, Pekín, Henán y Xiangyang (Nissan Global, 2017).

Además de las diferentes líneas de Toyota, esta empresa produce Scion, Daihatsu, Hino y Lexus. También se ha expandido por el mundo; en América tiene plantas en Estados Unidos, Canadá, Colombia, México, Venezuela, Ecuador, Brasil y Argentina. En Europa, sus ensambladoras se han ubicado en Polonia, República Checa, Reino Unido, Francia y Turquía. Además, tiene fábricas en Australia, Indonesia, Pakistán, India, Tailandia, Filipinas y la infaltable China (Toyota, 2017).

Volkswagen tiene cuarenta y cinco fábricas en veinte países para producir las marcas VW, Audi, Bentley, Bugatti, Lamborghini, Porshe, Seat, Skoda, Scania y MAN. En Europa tiene fábricas en Bélgica, Eslovaquia, Francia, Hungría, Italia, Polonia, Reino Unido, República Checa y Rusia. En América tiene ensambladoras en Estados Unidos, México, Brasil y Argentina. En el resto del mundo, tiene talleres en Sudáfrica, la India, Israel, Malasia y por supuesto en China (Volkswagen, 2017).

El grupo PSE, compuesto por Peugeot, Citroën y más recientemente Opel, además de múltiples talleres en Francia, en el viejo continente tiene fábricas en Madrid, Vigo, Figueruelas, Portugal, Eslovaquia, Rusia, Alemania y el Reino Unido. En América, sus instalaciones están en Buenos Aires y Porto Real en Brasil. Desde 1992 tiene en Dongfeng, China, una productora de cajas de cambio, desde 1995 una fábrica de motores en Xiangyang y en el 2010 construyó sus ensambladoras en Pekín y Shanghái (PSA, 2017). 
Incluso General Motors fabrica en China para el mercado doméstico a través de la alianza estratégica Shanghái-GM. También produce camiones y furgones bajo la marca Wuling (Esparza, 2010).

\section{CONCLUSIONES}

No es económicamente viable fabricar un automóvil cien por ciento estadounidense, ni alemán, ni japonés, ni chino.

Las materias primas para la fabricación de un automóvil tienen muy variados orígenes y sus fuentes están dispersas por el mundo entero. La producción de autopartes de calidad exige que las empresas se especialicen y dediquen tiempo y recursos a investigación y desarrollo. Por otra parte, los esquemas gerenciales se han venido adaptando y deberán adecuarse a niveles cada vez más exigentes de eficiencia, calidad, costos, plazos de entrega, manejo de inventarios, tecnologías, finanzas y mercadeo.

Es necesario agregar que la industria automotriz no termina con el embalaje portuario FOB (Free on Board). Antes bien, a partir de allí comienza una segunda parte de su cadena de valor. En esta nueva etapa participan las empresas navieras, las aseguradoras, el fisco, los concesionarios mercantiles, los creativos publicitarios, los medios masivos de comunicación y las instituciones financieras, hasta llegar al porcentaje por ventas que obtiene la persona que cierra cada venta individual.

La retórica proteccionista le impide al gobierno estadounidense ver que existen otras ganancias del libre comercio y que la contabilidad y las estadísticas de las transacciones internacionales requieren con urgencia de un cambio metodológico.

\section{REFERENCIAS}

Banco de Comercio Exterior (2017). La industria del aluminio en México. Revista Bancomex, 9, enero-marzo. Recuperado de: http://www.revistacomercioexterior.com/articulo.php?id=120

Business Insider (28 de enero, 2017). Trump cut regulation border tax imports. Recuperado de: http:// www.businessinsider.com/2017/01/28/

Cable News Network (2017). President Donald J. Trump's address to a joint session of congress. Recuperado de: http://www.cnn.on.line. com/2017/03/01/

CEPAL (2010). La inversión extranjera en América Latina y el Caribe. Informe 2009. Santiago de Chile: Naciones Unidas.

Esparza, Z. (2010). China: el nuevo gigante automotriz. Revista Análisis, 11(33). Jalisco: Universidad de Guadalajara.

Goodyear (2015). Goodyear announces new organizational structure. Recuperado de: http://corporate.gooyear.com/2015/12/01/

Forbes México (2017a). México 'se dobla' en el Mercado de aluminio. Recuperado de: http://www. forbes.com.mx/2017/03/06/

Forbes México (2017b). Las 20 compañías de pintura más grandes del mundo. Recuperado de: http:// www.forbes.com.mx/2017/03/07/

Groupe PSA. (2017). Sitio oficial. Recuperado de: https://www.groupe-psa.com/fr/

Hagerty J. y Bennett J. (25 de mayo, 2015). Los autos 'Made in USA' contienen cada vez más partes importadas. The Wall Street Journal, p.12.

Hill Ch. y Jones G. (1996). Administración estratégica. Un enfoque integrado. Bogotá: McGraw-Hill.

International Trade Administration. (2016). Steel Imports report: Global Steel Trade Monitor. Washington: Department of Commerce.

Juárez, H., Lara, A. y Bueno, C. (2005). El Auto Global. Desarrollo, competencia y cooperación en la in- 
dustria del automóvil. México: Universidad Iberoamericana.

La Nación (6 de marzo, 2017). Peugeot-Citroën será el segundo constructor de vehículos en Europa. La Nación, p. 20A.

Nissan Global (2017). Our company. Recuperado de: http://www.nissan-global.com/EN/COMPANY/ PROFILE/ESTABLISHMENT/

Rankia España. (2016). Los mayores productores de cobre del mundo. Recuperado de: http://www. rankia.com/2016/05/06/

Rodríguez, C. M. (2013). Oligopolio y competencia mundial en la industria automotriz. La emergencia del Toyotismo y la caída del Fordismo. Revista Economía Informa, 383, noviembre-diciembre, pp. 107-130.

Summers, D. (2006). Administración de la calidad. México: Pearson.

Tire Business. (2016). Bridgestone, líder mundial del mercado de neumáticos. Recuperado de: http:// www.tirebusiness.com/section/news
Toyota (2017). Sitio oficial. Recuperado de: http:// www.toyota.co.jp/

United Explanations (2015). ¿De dónde proviene el petróleo que se consume en Estados Unidos? Recuperado de: http://www.unaterexplanations. org/2015/09/14/.

USA Today (2017). President Trump promised to build a wall that runs along the entire U.S.-Mexico border. Recuperado de: http://www.usatoday. com/2017/01/26/.

Volkswagen (2017). Sitio web corporativo. Recuperado de: https://www.volkswagen.es/es.html.

Recibido: 22 de marzo 2017

Aceptado: 24 de agosto 2017 
This document was created with Win2PDF available at http://www.win2pdf.com. The unregistered version of Win2PDF is for evaluation or non-commercial use only. This page will not be added after purchasing Win2PDF. 